\title{
Teenage Pregnancy Policy in England
}

\author{
Roger Ingham
}

\begin{abstract}
This article provides an account of the development and early stages of the implementation of the teenage pregnancy policy introduced in England in 1999 (Social Exclusion Unit). The historical background of the policy is briefly outlined, followed by summaries of the processes involved, some of the key data that were drawn upon in its development, the content of the policy, evaluation data, critiques, and concluding comments. The policy is shown to have been based within a wider framework of attempts to reduce the number of young people who were thought to become socially excluded from society as a result of early childbearing. Emphasis in the policy was placed on both improved prevention of early conceptions through comprehensive sex and relationships education, improved services, and more open communication between parents and children and through improved support for those women who choose to have children in their teenage years.
\end{abstract}

Key words: teen pregnancy; sexual health; policy development; young parents

This article outlines the development and implementation of the teenage pregnancy policy (Social Exclusion Unit [SEU], 1999) in England over the past few years. In this article, the background to its development is summarized, together with the research base on which it drew and the early stages of its implementation and impact. Before this, however, a brief summary of general sexual health concerns prior to these recent initiatives is provided.

HIV emerged as an issue in the United Kingdom in about 1983, although a reluctance in higher government circles (at the time, a Conservative Government was in place) led to delays in responding to it; ${ }^{1}$ for example, government funding for a planned national survey of sexual behavior and attitudes was blocked (although this was subsequently funded by the Wellcome Trust and went ahead as originally planned). In due course, a national

1. Various off-the-record explanations have been received for these delays, none of which, however, is firm enough to record in print; Margaret (now Lady) Thatcher was the Conservative prime minister at the time.
HIV/AIDS campaign-involving extensive media advertising and an information leaflet distributed to all households-was launched, special earmarked allocations of money were distributed to local health authorities, and grants (albeit relatively small ones) were given to national and local voluntary organizations involved in awareness raising and prevention activities.

The first official central-government-level recognition of sexual health as a national health priority came in the 1991 Conservative Government white paper The Health of the Nation (Department of Health, 1992). This report identified key priority areas for action to improve the health of the general population; ${ }^{2}$ in relation to sexual health, targets were set to reduce by half the conception rates among women aged 15 years and under by the year 2000 and to reduce the rates of gonorrhea and of needlesharing by drug users. The gonorrhea target was set as a marker in response to the growth of HIV, which at the time

2. The other areas were coronary heart disease, cancers, accidents, and mental illness. 
was found primarily among men who had sex with men. The rate of gonorrhea had already been on a downward slope prior to the target being set, and the target was reached within 2 years of the publication of the white paper. More recently, a National Strategy for Sexual Health and HIV (Department of Health, 2001) has been published by the government, with a focus on the provision of improved health services, including earlier diagnosis and treatment of sexually transmitted infections.

Although The Health of the Nation (Department of Health, 1992) set this fairly challenging target to reduce by half the rates for under-16 conceptions, relatively little followed in terms of specific policies. Perhaps more importantly, little new finance was forthcoming to accomplish the goal, although a national telephone helpline was established in 1995 and there were a number of new local initiatives. By the year 2000, however, the overall rate of under-16 conceptions was very similar to that at the start of the period-about 8.5 per 1,00o women aged between 13 and 15 years (Office of National Statistics, 2002). ${ }^{3}$

The United Kingdom has a long tradition of fairly high numbers of teenage conceptions. Although the rates have shown a slight decrease over recent decades, this decline has been substantially lower than that observed in other western European countries. There have, however, been some significant changes during this period (Wellings \& Kane, 1999). First, the proportion of conceptions that end in termination has been rising steadily (leading to fewer births) and, second, the proportion of these teenage conceptions that have occurred within marriage or stable partnership has decreased markedly.

It was almost certainly this increase in the numbers of young single mothers that led, in 1998, to calls for action from the then recently elected Labour Government. As a major department in the Cabinet Office, the SEU is charged with exploring the reasons for people being excluded from mainstream society-for example, the jobless, those with poor educational attainment, and those living in overcrowded conditions-and finding remedies for such exclusion. One such group identified was young single parents, based on the evidence that early parenting was often associated with poorer physical and psychological outcomes for mothers and children and that early parenting was often passed on through generations (Kiernan, 1995).

The SEU comprises staff drawn from various government departments, as well as some temporarily

3. Under-16 rates are calculated per thousand women between ages 13 and 15 years, whereas under- 18 rates are reported per thousand women between ages 15 and 17 years (and teenage rates per thousand women aged between 15 and 19 years). employed people with particular expertise and experience in the topic under investigation. In response to the government's charge to study the issue of teenage pregnancy, the SEU appointed a team that commissioned some new research, discussed extensively the issues involved with a wide range of people, read a large number of reports and research articles on the topic, and visited areas in England as well as in other parts of Europe to examine the problem firsthand. Their report, Teenage Pregnancy (SEU, 1999), was submitted to Prime Minister Tony Blair in early 1999; Blair added a foreword and presented it to Parliament later in the year. This high-level support from national government gave the initiative a sense of purpose that it would not otherwise have had.

\section{The Teenage Pregnancy Policy}

\section{The Research Base}

Two key research themes prevailed in the SEU's (1999) report. The first concerned the strong relationship between indices of deprivation and the chances of early conception and the medium- and longer-term impact of teenage motherhood itself. Data from birth cohort longitudinal studies were presented that attempted to separate the relative impact of deprivation (or social exclusion) as a precursor of early pregnancy and motherhood from the deprivation that results from early parenthood (Hobcraft \& Kiernan, 1999). These data were used to help form the recommendations regarding prevention as well as those relating to finding better ways to support young people who choose to continue their pregnancies. The latter initiatives were intended to break the cycle of the crossgenerational pattern of early pregnancy and exclusion.

The report (SEU, 1999) described a number of risk factors for early pregnancy that had been identified by research in the United Kingdom and elsewhere; these included poverty, having been in public care, being a child of a teenage mother, having experienced educational problems, not being in an educational program after 16 years of age, having a history of being sexually abused, having a mental health problem, and having been involved in crime. It also cited research based on Kiernan's analyses of longitudinal data sources (the 1958 UK Birth Cohort study) that demonstrated the cumulative effect of multiple risk factors; thus, for example, women with five identified risk factors 4 had a $58 \%$ chance of becoming a

4. Risk factors included emotional problems at age 7 or 16 , mother was a teenage mother, family experienced financial adversity when they were 7 or 16 , a preference for being a young mother, and low educational attainment at age 16 . 
teenage mother compared with a chance of $3 \%$ for those with none of them (Kiernan, 1995). Ethnicity was also highlighted as a risk factor, although poor data collection, early marriage and childbearing patterns among some Asian (specifically Pakistani and Bangladeshi) populations, and the overlap between ethnicity and disadvantage made detailed analyses of these patterns difficult to achieve. Internal Department of Health analyses presented in the SEU's report also revealed variations in risk for teenage pregnancy based on location in addition to these other identified risk factors. Locations that scored similarly on indices of deprivation were found to have varying rates of early parenthood, indicating that cultural factors also played a role; those areas with higher rates included those whose economies were based on ports, industry, manufacturing, and coalfields.

The report (SEU, 1999) discussed why early pregnancy was an issue of concern, summarizing research findings on the poorer health outcomes for mother and baby, the greater chance of partnership dissolution for teenage mothers, the higher chance of postnatal depression among such mothers, their higher mobility, and the greater chance that they lived in poorer housing and had lower incomes. It also drew upon the results of longer-term follow-up of the 1958 UK birth cohort (Kiernan, 1995) that revealed that, by their mid-thirties, those who had become mothers in their teens suffered a range of disadvantages, including an increased probability of having no educational qualifications, being on state benefits, having lower incomes, having larger families, working in non-skilled occupations, and being less likely to be home owners. Logistic regression modeling enabled the relative influence of social disadvantage that was experienced prior to the birth to be separated from that which resulted from the early birth. These data helped to inform the elements of the strategy that were designed to increase the support available for young mothers.

The second main research evidence drawn upon in Teenage Pregnancy (SEU, 1999) was that concerned with cross-regional and cross-national variation. The former was used primarily to identify and illustrate the close relationship between area scores on various deprivation indices and rates of early conception (Clements, Stone, Diamond, \& Ingham, 1998). It was stressed, however, that even the least deprived areas of the United Kingdom had rates that were comparable to, or higher than, those in other European countries with much lower overall rates.

Comparisons with other countries, both in Europe and beyond, formed a major part of the analysis in the SEU's report (1999). A number of studies were commissioned especially for the report (for example, Cheesbrough,
Ingham, \& Massey, 1999; Kane \& Wellings, 1999), and previously published work was also drawn upon (for example, Ingham \& van Zessen, 1998; Jones, Forrest, \& Goldman, 1985). In addition to identifying economic issues (for example, that a high Gini coefficient, a measure of income and other forms of inequality, is associated with high teenage birthrates), the report paid attention to issues relating to sex education, services for young people, and general societal openness regarding sexual issues. The results of these studies, taken together, helped to reinforce the report's recommendations regarding the need for improvements in each of these areas, including the need for efforts to change the English culture surrounding sex and young people. Efforts to increase the extent of discussion between young people and their parents, for example, formed an important part of the strategy.

A further research study (Ingham, Clements, \& Gillibrand, 2001) that helped to support the direction of the recommendations in Teenage Pregnancy (SEU, 1999) had been commissioned by the Department of Health to explore variations in changes in under-16-year-old conceptions during the 1990s. Although, as mentioned earlier, the national target for halving these rates between 1992 and 2000 was not met nationally, there had been considerable local variation in accomplishing the goal. This study compared policy changes in the 20 local authorities that showed the largest decreases in rates of teenage pregnancy with those that showed the largest increases between 1992 and 1997. This study showed that the sites with decreasing rates were much more likely than those with increasing rates to have carried out one or more of the following: establish interagency groups, appoint new staff in education services to support sex education initiatives, provide additional specialist training for teachers, engage in consultation with young people, and establish new sexual health services targeted at young people.

In terms of sexual activity, comparative data were used in the report (SEU, 1999) to show that young people in Britain have a lower median age at first intercourse than do those in many other countries, along with lower levels of contraceptive use. One issue that particularly featured in the report was that the reported reasons for first-ever intercourse in the Netherlands (which has a considerably lower rate of teenage conceptions than does Britain) differed from those in the United Kingdom, especially among young men. Whereas in the United Kingdom only around $15 \%$ of men reported "love or commitment" as their main reason for intercourse, around 60\% did so in the Netherlands. Similarly, many fewer women in the Netherlands than in the United Kingdom reported regret regarding their first sexual experiences. These differences 
were interpreted in terms of greater openness in communication, both between parents and their children as well as between sexual partners, and greater gender equality in the Netherlands compared with the United Kingdom (Ingham \& van Zessen, 1998).

The report (SEU, 1999) also pointed to the patchy nature of school-based sex education in the United Kingdom, the apparent confusion that was experienced by teachers and others between what was compulsory and what was permissible to cover regarding sexuality, and the general dissatisfaction among young people regarding what sex education had been presented in their schools.

\section{The Strategy}

The strategy to reduce teenage pregnancy was launched upon the publication of the report Teenage Pregnancy by the SEU (1999). The report contained the Government's Action Plan, with 30 items listed under three main headings: a national campaign "to mobilise every section of society," better prevention of early conceptions, and better support for young parents. The full list of measures is shown in the Appendix.

The prime minister's foreword to the report (SEU, 1999) began by recognizing that Britain:

... has the worst record on teenage pregnancies in Europe. It is not a record in which we can take any pride.... Some of these teenagers, and some of their children, live happy and fulfilled lives. But far too many do not. (p. 4)

He went on to point out the non-inevitability of this pattern, noting that other western European countries had managed to reduce their rates of teenage parenthood quite substantially over the previous 30 years. His acceptance of the need to adopt a compromise between a moralistic stance and a pragmatic approach was well illustrated in the following statement from the foreword:

Let me make one point perfectly clear. I don't believe young people should have sex before they are 16. I have strong views on this. But I also know that no matter how much we disapprove, some do. We shouldn't condone their actions. But we should be ready to help them avoid the very real risks that under-age sex brings. The fact is that unprotected sex at any age is dangerous. (p. 4)

Based on the review of research, three factors were identified in the report (SEU, 1999) as the major reasons why the English rates of teenage pregnancy had not declined in line with those in other parts of western Europe:

- Low expectations among some young people (especially in the more deprived communities), with poor job prospects and a future likely to be dependent on the benefit system; in other words, "they see no reason not to get pregnant" (p. 7).

- Ignorance on the part of young people who lack adequate knowledge about contraception, STIs, and what is expected of relationships and parenthood.

- Mixed messages, or as one teenager is quoted as saying, "It sometimes seems that sex is compulsory but using contraception is illegal" (p. 7).

The contrast is drawn between the "bombardment" of teenagers with sexually explicit messages and impressions of sexual activity being normative, and the embarrassment and avoidance of the subject by parents and schools.

The report (SEU, 1999) then outlined the four key components of the action plan that aimed to achieve the identified targets:

- A national campaign ... to improve understanding and change behaviour.

- Joined-up action with new mechanisms to coordinate action at both national and local levels and ensure that the strategy is on track.

- Better prevention of the causes of teenage pregnancy, including better education in and out of school, access to contraception, and targeting of high-risk groups, with a new focus on reaching young men....

- Better support for pregnant teenagers and teenage parents, with a new focus on returning to education with child care to help, working to a position where no under-18 lone parent is put in a lone tenancy, and pilots around the country providing intensive support for parents and child. (p. 8)

A national Teenage Pregnancy Unit was established in 1999, and although officially it was a crossdepartmental unit (reporting to various ministerial departments), it was physically based in one of the Department of Health buildings. More recently, it moved to the Department for Education and Skills where it is now part of the recently established Children, Young People and Families Unit. The new priorities of this unit are described later in this article.

A new national cross-department high-level ministerial group was established, as well as an independent advisory group (comprising a range of practitioners, researchers, voluntary organizations, and others) to advise on strategy and monitor progress. At the local level, teenage pregnancy coordinators have been appointed in each of the approximately 140 local authority (units of local government) areas; some of these, in the early days, were allocated the task in addition to their regular post, while 
others were new appointments. As time has passed, however, most are now full-time posts, and each area has a high-level interagency Partnership Board 5 to guide local activities.

The national campaign comprises a series of fairly explicit (for Britain) advertisements (see examples in Figures 1, 2, and 3) in teenage magazines and other outlets, as well as national and local radio slots. The telephone number of a national helpline is provided and a website titled RU THINKING ABOUT IT was established specifically to support the activities (http://www.ruthinking.co.uk).

New guidance on what should be covered in schools was also developed (Department for Education and Employment [DfEE], 2001), and the school inspection service (Office for Standards in Education [Ofsted]) was reorganized to include units on Sex and Relationships Education (SRE) and Personal, Social, and Health Education (PSHE) within its remit (Ofsted, 2002). A new accreditation system for teachers was set up, and many local authorities have made use of this facility, although the total number of individuals trained under the system remains relatively low. Greater efforts were made to link school SRE provision with nearby clinics, but very few of the clinics are actually located on school premises. Most, if not all, health authorities have by now established facilities that are friendly to young people, normally with provisions for drop-ins, and all health care outlets have been reminded of the importance of confidentiality in their dealings with all clients. ${ }^{6}$ New training schemes have been established for health care staff to ensure that more are trained in working with young people in the area of sexuality and sexual health, and new guidance has been issued on these topics for a range of professional and voluntary sector workers. ${ }^{7}$

For those young people who decide to go ahead with a pregnancy, there are now national targets for the proportion who will return to education and employment, and financial help is available for child care costs. Those who are under 18 years old and who have no partner or who cannot live with their own parents are supposed to be offered supported housing, although progress toward this target has been somewhat slow. A new expanded

5 . These include representatives from various local government departments, including education, health, social services, housing, the voluntary sector, and others. 6 . There is provision for reporting details in cases where there is a strong suspicion of the need for child protection procedures and where the clinician assesses that a young person is not able to give fully informed consent.

7. These can be accessed via the Teenage Pregnancy Unit website at http://www.teenagepregnancyunit.gov.uk careers advice service, Connexions (see http://www. connexions.gov.uk), and special schemes to support young parents such as Sure Start Plus (see http://www. teenagepregnancyunit.gov.uk) have been established in various parts of the country, and the staff of these programs are expected to offer individual support for teenage parents. In addition, some local health authorities have created midwifery posts specifically to provide continuity of care for young mothers, and a means-tested Educational Maintenance Allowance, which provides finance to support those who wish to stay on in education after 16 years (the UK minimum age for leaving school), was made available for teen mothers. ${ }^{8}$

National resources for the implementation of the prevention and support activities available to teenage mothers were distributed to local authorities according to their size and the extent of their local rates. The money was to be spent on coordination and implementation of local plans, which needed to be submitted annually, and allocated resources were dependent on the vision and apparent success of these plans. However, while resources were earmarked for this work, this funding will no longer be "ring-fenced" after 2006, and it will then be up to local authority committees to decide on their own priorities for health and social services spending.

\section{Impact and Evaluation}

In the first 3 years after the introduction of the national teenage pregnancy strategy, the overall national rates of under-18 conceptions decreased by about $10 \%$. In the fourth year, the overall rate stayed roughly the same, but closer analysis revealed that there were decreases in $80 \%$ of local authority areas, with increases in the remaining 20\% (Office of National Statistics, 2005). It is of some interest that the areas that showed increases in the latest figures tended to be the more challenging areas in terms of the deprivation levels and the ethnic composition of the local populations and were congregated in London.

A large evaluation project was commissioned at the start of the strategy's implementation. ${ }^{9}$ This involved a range of activities, including regular national

8. This is means-tested and paid on top of other support and benefits provided by the government; for further details, see http://www.dfes.gov.uk/financialhelp/ema/ 9. The consortium comprises researchers from the London School of Hygiene and Tropical Medicine, University College London, and the British Market Research Bureau, under the direction of Kaye Wellings. Their final report is available at the Teenage Pregnancy Unit website: http://www.dfes.gov.uk/teenagepregnancy/dsp showDoc. cfm?FileName $=\mathrm{ACF}_{50 \mathrm{O}} \% 2 \mathrm{Epdf}$ 


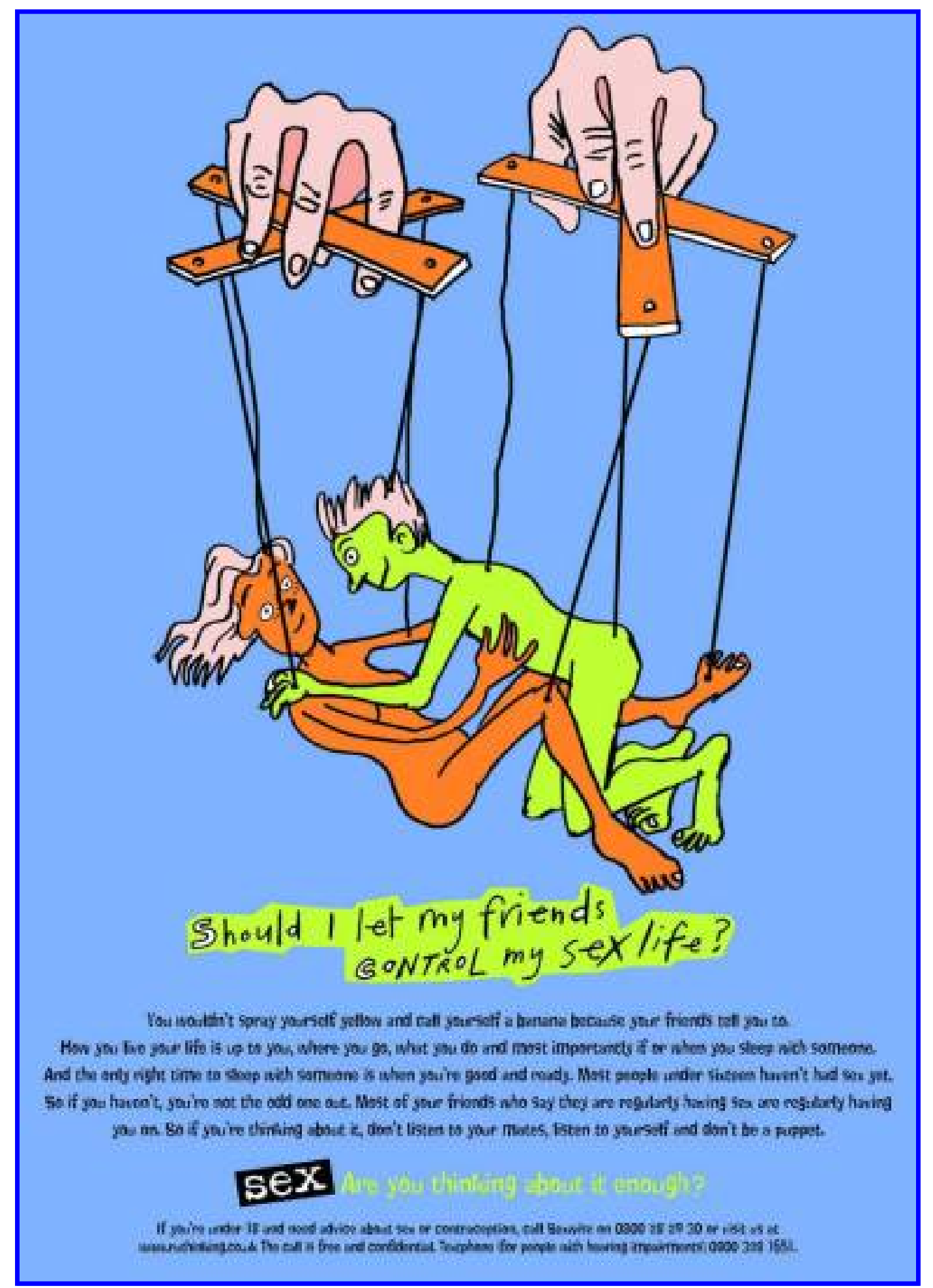

Figure 1. Sexual Health Campaign Advertisement: Should I let my friends control my sex life?*

* From the Department for Education and Skills, Her Majesty's Government, United Kingdom. Copyright 2005 by the Department for Education and Skills, London, England. Reprinted with permission. 


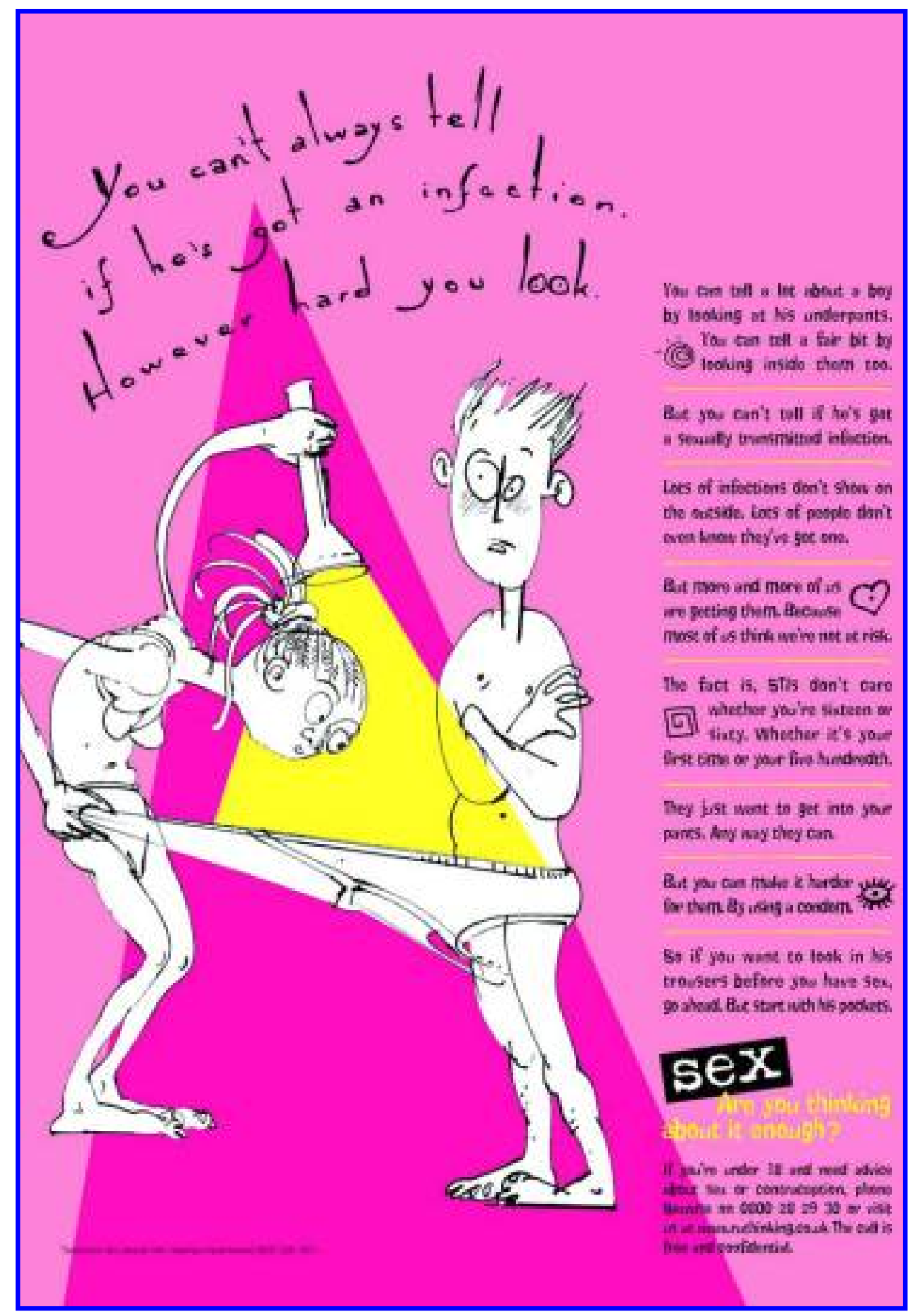

Figure 2. Sexual Health Campaign Advertisement: You can't always tell if he's got an infection.*

* From the Department for Education and Skills, Her Majesty's Government, United Kingdom. Copyright 2005 by the Department for Education and Skills, London, England. Reprinted with permission. 


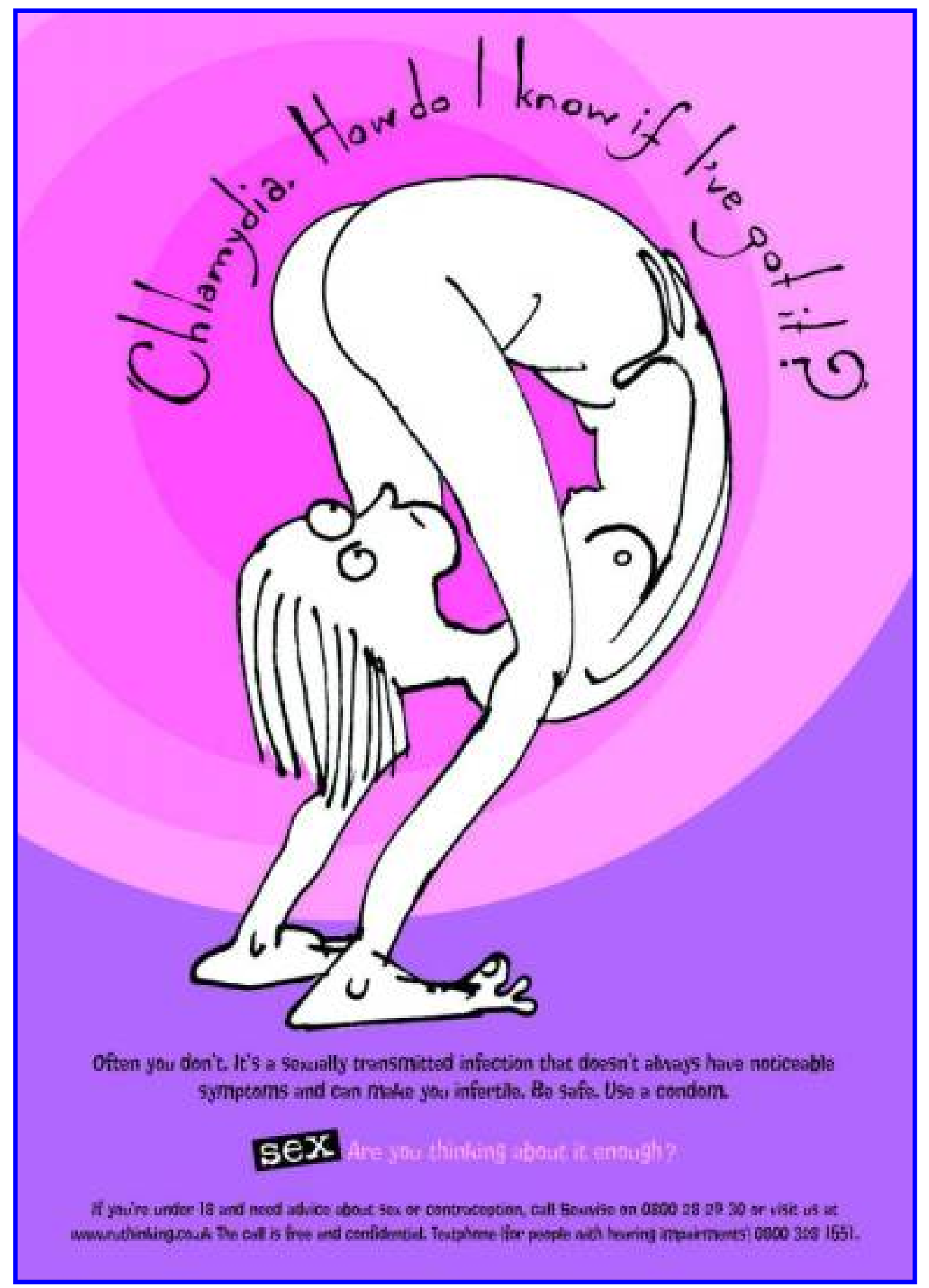

Figure 3. Sexual Health Campaign Advertisement: Chlamydia. How do I know if I've got it?*

* From the Department for Education and Skills, Her Majesty's Government, United Kingdom. Copyright 2005 by the Department for Education and Skills, London, England. Reprinted with permission. 
random-location tracking of the attitudes, knowledge, and behaviors related to the sexual health of young people and parents, interviews with young parents, monitoring of newspaper coverage of sexual health issues, awareness among young people of the radio and magazine campaign advertisements, detailed case studies of selected local sites, and evaluation of other aspects of the strategy.

The evaluation team reported strong support for the strategy's implementation at a local level among program coordinators and health professionals, with increasing numbers of specialist staff in position to support the strategy. There were frequent reports of greater acceptance of the need for action among some key gatekeepers who were initially less enthusiastic, and more attention is being given to education about sex and relationships in schools. The national accreditation scheme for teachers has been strongly welcomed, and interagency partnerships have appeared to work well, with some stable structures being established.

Direct evidence of change among young people from the tracking survey has been less clear-cut. Spontaneous recall of the campaign messages has increased over the past 3 years, as indeed have the numbers of young people who report calling the national Sexwise helpline (1.4 million annual callers in 2002 and 2003, with over half being young men) and using the dedicated website (at www.ruthinking.co.uk), with over 70,000 visits per month in 2004 (internal DfES audit data). These trends apply to the overall national data and, interestingly, those areas with larger decreases in rates of teenage pregnancy have been sites with greater campaign awareness and use of the helpline. A further encouraging result was that a higher proportion of young people reported that their sex and relationships education had "fully met" their needs.

An encouraging aspect of the evaluation arose from the monitoring of press coverage. Attention was paid to editorial and news coverage, as well as to paid campaign advertising, and the number of articles and types of papers in which they were published (national or local, broadsheet or tabloid, and positive, neutral, or negative toward the strategy's aims) were recorded. Over the 3 years since the strategy's inception, the extent of coverage increased and, perhaps more important, a greater proportion of published articles presented positive comments on the strategy. This may reflect a move toward greater societal acceptance of public discussion of the issues involved and the need to adopt a positive approach.

The greater support provided for young mothers in the United Kingdom is generally strongly welcomed. Personal advisors in areas where the system worked well appeared to be helping these mothers to access child care, benefits, and suitable employment or education opportunities. However, moves to provide supported housing for those who were on their own appeared to have made less substantial progress.

On the issue of access to education, training, and work, the target was for $60 \%$ of young mothers to have access to one or another, and the 3-year rolling average for 2002 to 2004 was almost 30\%, compared with $23 \%$ for 1997 to 1999 . There is clearly some way to go, but the $60 \%$ target did allow a fair amount of leeway for those young mothers who opted to concentrate on parenthood ahead of other options; the key challenge then will be whether these mothers will be able to obtain suitable education or training if they choose to do so at a later point.

\section{Critiques of the Approach}

The overall approach has come under some criticism from two directions. First, the religious/moral right (see, for example, Riches, 2004) has, not surprisingly, attacked the so-called contraceptive culture implied by the approach, the seeming lack of values inherent in the strategy, and the presumed threats made by it to the traditional family life structure of British society. The arguments drew fairly heavily on the rhetoric of the abstinence-only approach to sexuality education, although the UK government has remained (thus far) firm in its rejection of these arguments. Nonetheless, these attacks demanded frequent responses from local and national staff involved in the delivery of the strategy, as well as from politicians, even though the number of opponents was not large. From a similar direction, certain elements of the right-wing press (for example, the Daily Mail) regularly criticize the support given to young mothers-in child care payments as well as housing support-as encouraging early motherhood and dependency on the state.

The other line of questioning came from certain academic writers who were concerned with the government's conceptualization of the area. Kidger (2004) argued that the attempt to place more young mothers in education, training, or employment as a means to avoid long-term social exclusion was problematic because it "ignores the structural and contextual barriers to them gaining inclusion, it discounts full-time mothering as a valid option, and it neglects the social and moral elements of their exclusion, while in fact contributing to this" (p. 291). She referred to, but did not further discuss, earlier published analyses of whether teenage pregnancy should indeed be regarded as a problem at all (see, for example, Griffin, 1993; Phoenix, 1991) or the extent to which early motherhood adds to the probability of exclusion over and above those factors that lead some young women to be early mothers in the first 
place (see, for example, Hobcraft \& Kiernan, 2001; Kiernan, 2002).

This latter issue was to some extent also explored by Arai (2003), who questioned the emphasis in the strategy on technical/educational approaches-ones that provided more accessible contraception services and more open sex education-to the relative detriment of approaches that attempted to minimize the deprivation that is associated with much early pregnancy. Indeed, she questioned one of the key underpinning rationales for the English strategy-namely, that the rates are higher in the United Kingdom than in comparable northern European countries (such as the Netherlands, the Scandinavian countries, and Germany)-through discussion of the quite different socioeconomic structure and patterns of later youth transitions in these other countries.

These critiques raised important issues that need to be taken seriously. Although the government has not responded directly to them, were they to do so, I would suggest that they could point to two issues. First, while they might agree that reductions in economic disparities are an important long-term goal, these reductions will take several years to achieve and meanwhile action on the issue of teenage pregnancy is required. Second, they might argue that the target is to reduce the rates of under-18 conceptions, not births, and because approximately $45 \%$ of the current conceptions among this age group end in termination, those areas in which early childbearing is the traditional norm-and is to some extent chosen-are not necessarily the major immediate targets of the strategy. In other words, simply reducing a large proportion of those conceptions that are unplanned and unwanted-as evidenced by their ending in termination-would go a long way to achieving the target while more long-term structural initiatives should be directed toward the more deprived areas and those where early childbearing is a long-established feature.

\section{Summary and Conclusions}

It is probably too early to make any firm assessment of the specific impact of the teenage pregnancy strategy in the United Kingdom. This strategy certainly appears to have focused attention on the issue and to have provided some resources to enable local and national initiatives to be implemented. What may be of more interest, however, is how through this approach such a traditionally reserved culture as England's has started to open up regarding young people's sexuality. The country does have its objectors to this trend-a few but highly vocal family rights campaigners-but they have been relatively sidelined by the government over the past few years. On reflection, it may have been a particularly important move to express the issue as one being related to social exclusion rather than as one specifically targeted to increase sexual rights. From the social exclusion perspective, the issue then became one of pragmatism-what was demonstrated to work in other countries, what could be learned from these experiences, and what could be introduced into the United Kingdom. From this perspective, the overwhelming evidence pointed to the need for greater openness about sexuality, better education about the topic, and more available and accessible services, with associated training for staff. As it happens, such moves do increase young people's sexual health rights as well, but approaching the issue from an exclusion angle rather than from a rights perspective removed much of the potential opposition. There are still arguments about how to achieve the aims, of course, with calls for abstinence-only education being made by the family values campaigners, but there are no arguments about the intended outcomes.

The recent move to the Children, Young People and Families Unit in the Department for Education and Skills (DfES, formerly the DfEE) has added a further potential source of support for the initiatives that comprise the teenage pregnancy strategy. A recent discussion paper from the DfES (2004) outlined its new policy focus and called for more integrated child care services and monitoring to ensure that all children and young people are properly supported. As a result, all services directed to young people will now work toward five key outcomes: "Be healthy, stay safe, enjoy and achieve, make a positive contribution, and achieve economic well-being" (p. 23). Again, as with the concept of social exclusion, this new initiative adds further support for the need for good sexual health services. Under the heading of staying safe, the case for good early education to protect against abuse, coercion, and regretted early sexual activity can be strengthened, and as part of the goal of being healthy, the case for good services can be clearly stated.

As cultural change continues in the United Kingdom, as more and more teachers and health service staff become properly trained regarding sexuality, and as more parents and young people feel comfortable to talk with each other and with their partners about sex and contraception, the components of the strategy to prevent teenage pregnancy can become more ingrained into English culture, hopefully ensuring that the progress made in the past few years will be harder to reverse should a new regime attempt to do so in the future.

\section{References}

Arai, L. (2003). British policy on teenage pregnancy and childbearing: The limitations of comparisons with 
other European countries. Critical Social Policy, 74, 89-102.

Cheesbrough, S., Ingham, R., \& Massey, D. (1999). Reducing the rates of teenage conceptions. An international review of the evidence: The United States, Canada, Australia and New Zealand. London: Health Education Authority.

Clements, S., Stone, N., Diamond, I., \& Ingham, R. (1998). Modelling the spatial distribution of teenage conception rates within Wessex. British Journal of Family Planning, 24(2), 61-71.

Department for Education and Employment. (2001). Sex and relationship education guidance. London: Department for Education and Employment.

Department for Education and Skills. (2004). Every child matters: Next steps. London: Department for Education and Skills.

Department of Health (1992). The health of the nation. London: The Stationery Office.

Department of Health (2001). The national strategy for sexual health and HIV. London: The Stationery Office.

Griffin, C. (1993). Representations of youth: The study of youth and adolescence in Britain and America. Cambridge: Polity Press.

Hobcraft, J., \& Kiernan, K. (1999). Childhood poverty, early motherhood and adult social exclusion. Analysis for the SEU, CASE paper 28. London: London School of Economics.

Hobcraft, J., \& Kiernan, K. (2001). Childhood poverty, early motherhood and adult social exclusion. British Journal of Sociology, 52, 495-517.

Ingham, R., \& van Zessen, G. (1998, January). From cultural contexts to interactional competencies: A European comparative study. Paper presented at the AIDS in Europe conference, Paris.

Ingham, R., Clements, S., \& Gillibrand, R. (2001). Factors affecting changes in rates of teenage conceptions. London: Teenage Pregnancy Unit.
Jones, E. F., Forrest, J. D., Goldman, N., Henshaw, S. K., Lincoln, R., Rosoff, J. I., et al. (1985). Teenage pregnancy in developed countries; Determinants and policy implications. Family Planning Perspectives, $17(2), 53-63$.

Kane, R., \& Wellings, K. (1999). Reducing the rate of teenage conceptions: Data from Europe. London: Health Education Authority.

Kidger, J. (2004). Including young mothers: Limitations to New Labour's strategy for supporting teenage parents. Critical Social Policy, 24, 291-311.

Kiernan, K. (1995). Transition to parenthood: Young mothers, young fathers-associated factors and later life experiences. Welfare State Programme, discussion paper WSP/113. London: London School of Economics.

Kiernan, K. (2002). Disadvantage and demography: Chicken and egg? In J. Hills, J. LeGrand, \& D. Piachaud (Eds.), Understanding social exclusion (pp. 84-96). Oxford: Oxford University Press.

Office of National Statistics. (2002). Health Statistics Quarterly 14, Summer 2002. London: ONS.

Office of National Statistics. (2005). Under-18 conceptions data for top-tier local authorities (LAD1), 1998-2003. London: Office of National Statistics.

Office for Standards in Education. (2002). Sex and relationships education. London: Office for Standards in Education.

Phoenix, A. (1991). Young mothers? Cambridge: Polity Press.

Riches, V. (2004). Sex education or indoctrination? How ideology has triumphed over facts. London: Family and Youth Concern.

Social Exclusion Unit. (1999). Teenage pregnancy. London: The Stationery Office (Cmnd 4342).

Wellings, K., \& Kane, R. (1999) Trends in teenage pregnancy in England and Wales; how can we explain them? J. Royal Society of Medicine, 92, 277-282. 


\section{Appendix}

Summary of the Teenage Pregnancy 30-point Action Plan (SEU, 1999, pp. 91-102)

\section{National campaign}

1. Establish clear goals (halve rates of under-18 conceptions, achieve a reduction in the risk of longterm social exclusion for teenage parents and their children)

2. National coordination (cross-departmental ministerial task force and unit in Department of Health)

3. Independent Advisory Group on Teenage Pregnancy (set up group of wide range of views to advise Government)

4. Local implementation (each local authority to identify a coordinator who will work to develop local programmes)

5. Support coordinators (national and regional support for coordinators)

6. Monitor progress (develop benchmarks for monitoring progress and commission evaluation)

7. Promotion and communication (co-fund a national media campaign to reinforce messages)

\section{Better education about sex and relationships in schools}

8. Develop new guidance on sex education in schools (new national guidance, support for local policies, encourage parental involvement)

9. Link sex education to a broader framework of personal education

10. Teacher training and accreditation in SRE (review content of all initial teacher training and develop specialist training)

11. Inspection (school inspections will cover SRE policies)

\section{Involving parents in prevention}

12. Help parents to talk to their children about sex and relationships (national campaign, using parents as peer educators)

\section{Effective advice and contraception for young people}

13. Clearer guidance for all health professionals on contraception for under-16s

14. New National Health Service criteria for effective and responsible youth contraception and advice services (accessibility, well publicized, effective, open to all, responsible)
15. National helpline

16. Get young people to seek advice (national publicity campaign)

Boys and young men

17. Publicity (ensure that young men are more aware of responsibilities about contraception and young parenthood)

18. Child support (ensure that nonresident young fathers contribute financially to their children's costs)

19. Age of consent (reconsider the age defense in the Sexual Offences Act 1956)

\section{Prevention for groups at special risk}

20. Children in care, care leavers, and other children in need (new guidance for staff working in these areas)

21. Young offenders (each young offenders institution to offer sexual health and parenting classes)

22. Ethnic minority groups (local coordinators to work with local communities to develop better information on patterns and more appropriate initiatives)

\section{Supporting teenage parents}

23. Getting back into education-under-16s (under-16 mothers will be required to continue their education)

24. Getting back into education-16- and 17-year-olds (education maintenance allowances to enable continued education)

25. Advice for the over-16s claiming benefit (personal advisors to discuss options for education and training)

26. Help with child care for 16 - and 17-year-olds returning to education (subsidized child care places for this group)

27. Advice and support for pregnant under-18s (personal advice on services available for all women in this group)

28. Sure Start Plus-personal support for pregnant teenagers and teenage parents under 18 years (coordinated support for the groups involving pregnancy advisors and new tailored support packages)

\section{Housing for under-18 lone parents}

29. Social housing; supervised semi-independent housing with support for under-18 lone parents (all unsupported under-18 mothers to be offered supervised housing)

30. Extending same principle to private rented sector through housing benefit (develop benefit system to enable semi-independent supervised housing) 